\title{
Speciation analysis of chromium in drinking water samples by ion-pair reversed-phase HPLC-ICP-MS: validation of the analytical method and evaluation of the uncertainty budget
}

\author{
Danuta Barałkiewicz • Barbara Pikosz • \\ Magdalena Belter $\cdot$ Monika Marcinkowska
}

Received: 20 February 2013/Accepted: 16 July 2013/Published online: 4 August 2013

(C) The Author(s) 2013. This article is published with open access at Springerlink.com

\begin{abstract}
The approach presented in this article refers to the modification of a method for the detection and quantitative determination of chromium species in water by high-performance liquid chromatography inductively coupled plasma mass spectrometry. The main aim of this work was to establish a detailed validation of the analytical procedure and an estimation of the budget of measurement uncertainty which was helpful in recognizing the critical points of the presented method. As a result of the method validation experiment, the obtained limit of quantification, repeatability and intermediate precision were satisfied for the quantification $\mathrm{Cr}(\mathrm{III})$ and $\mathrm{Cr}(\mathrm{VI})$ in water matrices. The trueness of the method was verified via an estimation of the recovery of the spiked real samples. The recovery rate of both determined analytes was found to be between 93 and $115 \%$. Considering that the validation of the method and the evaluation of measurement uncertainty are crucial for quantitative analysis, the above-mentioned assessment of the uncertainty budget was performed in two different ways: a modelling approach and a single-laboratory validation approach. The measurement uncertainties of the results were found to be 4.4 and $7.8 \%$ for $\mathrm{Cr}(\mathrm{III}), 4.2$ and $7.9 \%$ for $\mathrm{Cr}(\mathrm{VI})$ using the classical concept and method validation data, respectively. This paper is the first publication to presenting all the steps needed to evaluate the measurement uncertainty for the speciation analysis of chromium species. In summary, the obtained results
\end{abstract}

D. Barałkiewicz $(\bowtie) \cdot$ B. Pikosz $\cdot$ M. Belter

M. Marcinkowska

Department of Trace Element Analysis by Spectroscopy

Method, Faculty of Chemistry, Adam Mickiewicz University in

Poznan, 89b Umultowska Street, Poznan, Poland

e-mail: danutaba@amu.edu.pl demonstrate that the method can be applied effectively for its intended use.

Keywords Method validation .

Measurement uncertainty - Speciation analysis ·

Chromium species $\cdot$ HPLC-ICP-MS

\section{Introduction}

The approach of hyphenating chromatographic methods to ICP-MS is a powerful tool for elemental speciation in environmental sciences [1]. The number of applications of HPLC-ICP-MS in speciation analysis is advancing, and the speciation of different biologically active compounds, including ions with different oxidation states, is a growing area of research [2-5]. Among elements, $\mathrm{Cr}$ is obviously of particular interest, as it is widely distributed in the environment due to its many industrial applications, e.g. in galvanization and the steel industry [6]. It exists in several species of which $\mathrm{Cr}$ (III) is considered to be an essential nutrient for the human body at the trace level, whereas $\mathrm{Cr}(\mathrm{VI})$ is thought to be highly toxic owing to its high oxidation potential and the ease with which it penetrates biological membranes [7]. This is the reason why speciation analysis of $\mathrm{Cr}$, particularly in drinking water, has already been investigated extensively. Nowadays, in European Union countries (including Poland), the permissible total chromium content in drinking water, recommended by the World Health Organization (WHO), is $50 \mu \mathrm{g} \mathrm{L}^{-1}$. Consequently, there is a need to develop a reliable method for the determination of $\mathrm{Cr}$ species in water, in order to create relevant legal norms. However, the accurate quantification of the species presents a challenge to the analytical sciences. The presentation of an analytical 
result must be accompanied by some indication of the data quality. This information is essential for the interpretation of the analytical result. The comparison of two results cannot be made without the knowledge of their quality.

The HPLC-ICP-MS technique is considered to be a good option for determining of chromium species in water samples. As one of the most sensitive and robust detectors, ICP-MS offers pronounced advantages for its elemental specificity, wide linear dynamic range and extremely low detection limits [8]. The technology dynamic reaction cell (DRC) with ICP-MS greatly reduces the spectroscopic interferences of ${ }^{40} \mathrm{Ar}^{12} \mathrm{C}^{+}$and ${ }^{35} \mathrm{Cl}^{16} \mathrm{O}^{1} \mathrm{H}^{+}$and thus improves the sensitivity of chromium analysis [9]. The chromatographic methods for chromium speciation analysis may involve either ion chromatography (IC) $[10,11]$ or ion-pair reversed-phase chromatography (RPIPC) [12, 13]. RPIP-HPLC is widely used as a simple, flexible and sensitive method for separating chromium compounds.

The proposed revised method facilitates the determination of specific chromium species at low concentration levels in water matrices. Therefore, it is extremely important to prove the reliability of the results. In spite of the numerous articles published in this domain, no fully validated method has yet been established; this is especially the case concerning demonstration of the traceability of speciation analysis and the measurement of uncertainty evaluation. The purpose of this study is to perform a detailed validation of the analytical procedure and estimate the uncertainty budget of measurement for determination of $\mathrm{Cr}(\mathrm{III})$ and $\mathrm{Cr}(\mathrm{VI})$ in drinking water using RPIP-HPLCICP-MS. The method was validated according to the international guidelines ISO/IEC 17025:2005 [14]. The assessment of uncertainty was carried out using a modelling approach and single-laboratory validation approach. A full combined uncertainty calculation including possible sources of uncertainty was reported.

\section{Experimental}

\section{Instrumentation}

The separation of chromium species was performed on a PerkinElmer Series 200 HPLC system. A reversed-phase C8 Brownlee cartridge column (PerkinElmer, Pecosphere, $3 \mu \mathrm{m}$ diameter particles, $4.6 \mathrm{~mm}$ i.d. $\times 33 \mathrm{~mm}$ length) with a column holder (PerkinElmer) was used. The abovementioned HPLC system consisted of a vacuum degasser, peltier-cooled autosampler tray, quaternary gradient pump and a peltier-heated column oven. This assembly was also equipped with an automatic switching valve (Rheodyne, Rohnet Park, CA, USA) that allowed the authors to operate
Table 1 Optimized operational conditions for HPLC-ICP-MS

\begin{tabular}{|c|c|}
\hline \multicolumn{2}{|l|}{ HPLC conditions } \\
\hline Column & PerkinElmer C8 $(3.3 \mathrm{~mm}, 3 \mu \mathrm{m})$ \\
\hline Colum temperature & $25^{\circ} \mathrm{C}$ \\
\hline Mobile phase & $\begin{array}{l}0.8 \mathrm{mmol} \mathrm{L}^{-1} \mathrm{TBAH}, \\
0.6 \mathrm{mmol} \mathrm{L}^{-1} \text { EDTA, } \mathrm{pH}=6.9\end{array}$ \\
\hline Elution program & Isocratic \\
\hline Mobile phase flow rate & $1.2 \mathrm{~mL} \mathrm{~min}^{-1}$ \\
\hline Sample injection volume & $50 \mu \mathrm{L}$ \\
\hline Total analysis time & $3 \mathrm{~min}$ \\
\hline \multicolumn{2}{|l|}{ ICP-MS conditions } \\
\hline Nebulizer & Meinhard quartz concentric \\
\hline Spray chamber & Quartz cyclonic \\
\hline RF power & $1050 \mathrm{~W}$ \\
\hline Plasma gas flow & Ar, $15 \mathrm{~L} \mathrm{~min}^{-1}$ \\
\hline Nebulizer gas flow & Ar, $0.88 \mathrm{~L} \mathrm{~min}^{-1}$ \\
\hline Auxiliary gas flow & Ar, $1.2 \mathrm{~L} \mathrm{~min}^{-1}$ \\
\hline Monitored ion $\left(m / z^{+}\right)$ & ${ }^{52} \mathrm{Cr}^{+}$ \\
\hline Reaction gas & $\mathrm{NH}_{3}$ \\
\hline Reaction gas flow rate & $0.5 \mathrm{~mL} \mathrm{~min} \operatorname{mon}^{-1}$ \\
\hline Rejection parameter $q$ & 0.7 \\
\hline
\end{tabular}

between the HPLC and the ICP-MS sample introduction system.

An Elan DRC II ICP-MS (PerkinElmerSCIEX, Canada) instrument was utilized in this experiment for the elemental detection of $\mathrm{Cr}$ at $\mathrm{m} / \mathrm{z}^{+}$52. Using ammonia as the reaction gas in the DRC technology caused the removal of a great part of the polyatomic interferences, predominantly ${ }^{40} \mathrm{Ar}^{12} \mathrm{C}^{+}$and ${ }^{35} \mathrm{Cl}^{16} \mathrm{O}^{1} \mathrm{H}^{+}$occurring in chromium determination. The gas flow rate and a rejection parameter $q(R P q)$ were optimized to reach the maximum signal to noise $(S / N)$ ratio. Details of HPLC and ICP-MS operating conditions are listed in Table 1.

Standards and reagents

Reagents were analytical grade chemicals and were used without further purification. All standards and solutions including a mobile phase were prepared with ultrapure deionized water $(18.2 \mathrm{M} \Omega \mathrm{cm}$, Smart2Pure, TKA Water Purification Systems, Germany). Standard solution of $1 \mathrm{mg} \mathrm{L}^{-1} \mathrm{Cr}(\mathrm{III})$ was prepared by diluting the stock solution of $\mathrm{Cr}^{3+}\left(\mathrm{Cr}\left(\mathrm{NO}_{3}\right)_{3}\right)$ at $1000 \mathrm{mg} \mathrm{L}^{-1}$ (Merck, Darmstadt, Germany) in deionized water. A stock solution of $1000 \mathrm{mg} \mathrm{L}^{-1} \mathrm{Cr}^{6+}$ was made by dissolution of the appropriate amount of potassium chromate $\left(\mathrm{K}_{2} \mathrm{CrO}_{4}\right.$, Merck, Darmstadt, Germany) in deionized water. The solution was then acidified with nitric acid (65\% volume concentration of $\mathrm{HNO}_{3}$ suprapur, Merck, Darmstadt, Germany) to obtain an orange solution of potassium 
dichromate $\left(\mathrm{K}_{2} \mathrm{Cr}_{2} \mathrm{O}_{7}\right)$. Standard solution of $1 \mathrm{mg} \mathrm{L}^{-1} \mathrm{Cr}(\mathrm{VI})$ was obtained by diluting the stock solution of $1000 \mathrm{mg} \mathrm{L}^{-1}$ $\mathrm{Cr}^{6+}$. The solutions were stored in glass flasks at $4{ }^{\circ} \mathrm{C}$ to minimize the interconversion between these two species. A mobile phase was obtained by dissolution of an appropriate amount of ethylenediaminetetraacetic acid dipotassium salt dehydrate (EDTA, Sigma-Aldrich, Spain) in deionized water and by the addition of tetrabutylammonium hydroxide (TBAH, $1.0 \mathrm{~mol} \mathrm{~L}^{-1}$ solution in water, Fluka Analytical, Switzerland). The solution was filtered through a $0.20-\mu \mathrm{m}$ cellulose acetate membrane filter prior to analysis. Calibration standards at different concentrations containing mixed chromium species were prepared about $1 \mathrm{~h}$ before analysis by appropriate dilution standards solutions of $\mathrm{Cr}(\mathrm{III})$ and $\mathrm{Cr}(\mathrm{VI})$ in mobile phase and were kept at an ambient temperature. This assured the formation of a $[\mathrm{CrEDTA}]^{-}$complex with the greatest efficiency.

\section{Sample collection and preparation}

An analytical procedure validation was carried out on drinking water samples, which came from four water purification plants situated in the western and north-western part of Poland. The samples were collected in $100 \mathrm{~mL}$ polyethylene bottles and were immediately frozen until further use. The samples were de-frosted directly before analysis. The examined water was filtered through a 0.2$\mu \mathrm{m}$ pore-size regenerated cellulose syringe filter to remove suspended matter from the samples (because the study was focused only on determination of the specific metal species present in the dissolved fraction) and extend the HLPC column life. Drinking water samples were diluted to $3: 1$ (volume to volume) with the mobile phase. These solutions were kept in glass vials at an ambient temperature for about

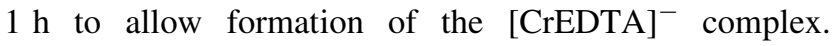
Analyses of the samples were conducted both with and without an analytical spike of each chromium species.

\section{Method development}

The chromium species, $\mathrm{Cr}(\mathrm{III})$ and $\mathrm{Cr}(\mathrm{VI})$, were separated using the RPIP-HPLC method. For this process, following other researches [12, 15-17], EDTA was employed as the $\mathrm{Cr}(\mathrm{III}$ - - complexing agent and TBAH as the ion-pair reagent. Numerous parameters such as EDTA and TBAH concentrations, $\mathrm{pH}$ and methanol concentration of the mobile phase influenced the separation of chromium species. After optimization of chromatographic conditions, the HPLC mobile phase consisted of $0.6 \mathrm{~mol} \mathrm{~L}^{-1}$ EDTA and $0.8 \mathrm{mmol} \mathrm{L}{ }^{-1} \mathrm{TBAH}$; $\mathrm{pH}$ was adjusted to 6.9 with $\mathrm{HNO}_{3}$ solution [diluted 1:10 (volume to volume)]. Unlike most previous papers $[12,15,16]$, methanol was not adopted in the presented article. It is known that, the addition of an organic solvent to the mobile phase leads to a shortening of the retention times of organic forms and to narrowing peaks. However, the elimination of methanol was advantageous due to the three following reasons: (1) reducing the polyatomic interference occurring on ${ }^{52} \mathrm{Cr}^{+}$determination; (2) preventing carbon accumulation on the sampling and skimmer ICP-MS cones and clogging them; (3) improvement of the chromium detection limit [3]. In spite of the absence of methanol in the mobile phase, the total time of analysis was quite short and satisfactory.

Calculation and statistical methods

Chromera software (version 2.1.0.1631, purchased from PerkinElmerSCIEX) allowed for the automated handling of the HPLC and ICP-MS systems. All required calculations such as background subtraction, integration of peak areas, as well chromatograms plotting were made using the same software. Additionally, some statistical tests were performed: Dixon's $Q$ test, Snedecor's $F$ test and Student's $t$ test. In order to reject results with gross errors, to each sets of measurements mentioned below, Dixon's $Q$ test was used. Some of these tests including Snedecor's $F$ test and Student's $t$ test are described later in the paper.

\section{Results and discussion}

A validation of the analytical procedure for quantitative determination of $\mathrm{Cr}(\mathrm{III})$ and $\mathrm{Cr}(\mathrm{VI})$ in drinking water samples was performed. The subsequent parameters were evaluated: selectivity and specificity, linearity, limit of detection (LOD) and limit of quantification (LOQ), precision, trueness and uncertainty estimation.

\section{Selectivity and specificity}

In order to determine the separation of $\mathrm{Cr}(\mathrm{III})$ and $\mathrm{Cr}(\mathrm{VI})$, a working standard solution containing both $\mathrm{Cr}$ forms at $10 \mu \mathrm{g} \mathrm{L}^{-1}$ were analyzed $(n=5)$ and their retention times were measured. Figure 1 indicates the complete separation of the $[\mathrm{CrEDTA}]^{-}$complex and $\mathrm{Cr}(\mathrm{VI})$ under optimum HPLC conditions. As can be seen from the chromatogram, retention times are $1.42 \mathrm{~min}$ and $1.92 \mathrm{~min}$ for $\mathrm{Cr}(\mathrm{III})$ and $\mathrm{Cr}(\mathrm{VI})$, respectively. Compared to previous experiments [12, 15-17], the reported retention times are similar or slightly higher.

\section{Linearity}

The operating range was determined by statistical analysis (Snedecor's $F$ test) by checking the homogeneity of variances for the extreme concentration levels of analytes. The $F$ value was calculated according to the literature [18]. 
Fig. 1 Typical separation chromatogram of the [CrEDTA $^{-}$complex and $\mathrm{Cr}(\mathrm{VI})$ obtained by using optimized the HPLC-ICP-MS procedure. Indications from standards constructing sevenpoint calibration curves for both analytes are presented: $0.3 ; 1.0$; $2.0 ; 3.0 ; 5.0 ; 7.5$; and $10 \mu \mathrm{g} \mathrm{L}^{-1}$

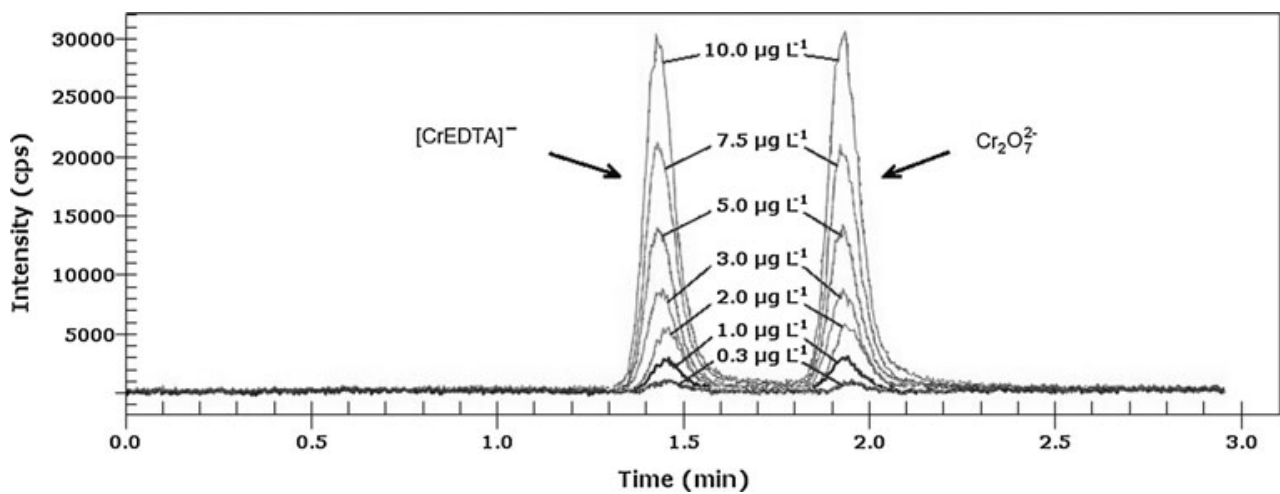

In this study, the $F$ values were estimated for the concentration limits for the calibration curves: 0.3 and $10 \mu \mathrm{g} \mathrm{L}^{-1}$ for chromium species. In both cases, $F \leq F_{\text {crit }}$. It may be concluded that the variances calculated for the compared series of results do not differ in a statistically significant manner. Thus, it seemed that in this extent, the calibration curves were chosen correctly.

Afterwards, calibration curves were obtained by preparing and measuring in triplicates seven concentration levels $\left(0.3 ; 1.0 ; 2.0 ; 3.0 ; 5.0 ; 7.5\right.$; and $\left.10 \mu \mathrm{g} \mathrm{L}^{-1}\right)$ for each chromium species. In both cases, the correlation coefficient was close to $1(r=0.9999)$ for $\mathrm{Cr}(\mathrm{III})$ and $\mathrm{Cr}(\mathrm{VI})$. The sensitivity for $\mathrm{Cr}(\mathrm{VI})$ was higher than for $\mathrm{Cr}$ (III). In order to confirm the difference between these two sensitivities, the Student's $t$ test was carried out. It showed that the sensitivities of both chromium species differ in a statistically significant manner.

To check the linearity, a procedure based on the drawing of a so-called graph of constant response was applied. The method is described by the expression: $f(x)=y / x$, where $y$ denotes the indication and $x$ the concentration of an analyte in the standard sample corresponding to a given indication. On the graph, the arithmetic mean of individual values $f(x)$ with an acceptable deviation (accepted deviation is $\pm 5 \%$ ) are marked as lines parallel to the $X$ axis. Points lying outside the defined scope should be rejected when creating a calibration curve. They correspond to analyte concentrations that lie outside the linear range of the measuring equipment [18].

Mean values of $f(x)$ for all concentration levels for $\mathrm{Cr}$ (III) as well as $\mathrm{Cr}$ (VI) obtained in this work are inside the defined scope. It may be inferred that all points of the calibration curves lie inside the linear range of the measuring equipment.

\section{LOD and LOQ}

In general, LOD is defined as the lowest possible concentration that can be measured reliably. This value is mainly calculated as three times the standard deviation of the signal from blank sample-blank determination method [2, $15,16]$. However, in the literature, there are several different methods for determination of LOD, for instance: modified blank determination method, graphical method and linear regression method. In presented article, these three different methods were developed to determine LOD:

- modified blank determination method-calculation based on determination for blank samples with quantifiable amounts of the analyte: $\mathrm{LOD}=3 s$, where $s$ denotes the standard deviation of 10 independent measurements $(n=3)$ for samples with $0.5 \mu \mathrm{g} \mathrm{L}^{-1}$ of both chromium species [18, 19];

- graphical method-plot obtained from standard deviations for three standard solutions, $0.3 ; 0.4 ; 0.5 \mu \mathrm{g} \mathrm{L}^{-1}$ of $\mathrm{Cr}(\mathrm{III})$ and $\mathrm{Cr}(\mathrm{VI})(n=6)$ was used to calculate LOD according to the formula: LOD $=3 s_{\mathrm{o}}$, where $s_{\mathrm{O}}$ denotes intercept [18];

- linear regression method-calculation based on standard deviation of signals and slope of the calibration curve (standard deviation/slope ratio): $\mathrm{LOD}=3.3 \mathrm{~s} / \mathrm{b}$, where $s$ denotes the standard deviation of the response (estimated based on the calibration curve), $b$ the slope of the calibration curve $[18,23]$.

Each of described approach is widely accepted and metrologically correct.

Limit of quantification is the lowest concentration of analyte that can be determined with an acceptable level of precision and trueness. In this study, it was calculated as 3 times the LOD. Using the HPLC-ICP-MS method, LOD was found to be 0.094 and $0.10 \mu \mathrm{g} \mathrm{L}^{-1}$ for $\mathrm{Cr}$ (III) and $\mathrm{Cr}$ (VI), respectively, according to the modified blank determination method (LOQ for $\mathrm{Cr}$ (III) is $0.28 \mu \mathrm{g} \mathrm{L}^{-1}$ and for $\mathrm{Cr}$ (VI) is $\left.0.30 \mu \mathrm{g} \mathrm{L}^{-1}\right)$. This approach was approved because LOD values for chromium species at the mass $\mathrm{m} / \mathrm{z}^{+} 52$ were mainly calculated by previous authors as the 3 times the standard deviation of the background (Table 2). Therefore, the obtained results could be readily compared to others. The LOD values demonstrated in this work are correspondingly or slightly higher than the former HPLC-ICP-MS outcomes. 
Table 2 Detection limits of chromium species (literature data)

\begin{tabular}{|c|c|c|c|c|}
\hline \multicolumn{2}{|c|}{$\operatorname{LOD}\left(\mu \mathrm{g} \mathrm{L}^{-1}\right)$} & \multirow[t]{2}{*}{ Sample volume $(\mu \mathrm{L})$} & \multirow[t]{2}{*}{ Method for determination of LOD } & \multirow[t]{2}{*}{ References } \\
\hline${ }^{52} \mathrm{Cr}(\mathrm{III})$ & ${ }^{52} \mathrm{Cr}(\mathrm{VI})$ & & & \\
\hline 0.09 & 0.10 & 50 & Modified blank determination method & This work \\
\hline 0.05 & 0.05 & 200 & Blank determination method & {$[2]$} \\
\hline 0.04 & 0.02 & 50 & & {$[5]$} \\
\hline 0.063 & 0.061 & 100 & & [15] \\
\hline 0.08 & 0.19 & 20 & & {$[20]$} \\
\hline 0.3 & 0.4 & 50 & Based on $S / N$ ratio & [10] \\
\hline 0.09 & 0.06 & 50 & & {$[12]$} \\
\hline 0.05 & 0.05 & 50 & & {$[16]$} \\
\hline 0.03 & 0.03 & 100 & No data available & {$[3]$} \\
\hline 0.32 & 0.19 & 100 & & {$[21]$} \\
\hline 0.005 & 0.012 & 1000 & & {$[22]$} \\
\hline
\end{tabular}

Authors rarely give the value of the obtained LOQ and the manner of its designation. The most commonly employed method is to evaluate LOQ as 3 times the LOD [1]. In some papers, LOQ was calculated as 10 times the LOD, 6 or 10 times the standard deviation of the blank sample [24-26]. Other authors have estimated LOQ using the standard deviation/slope method described above [27, 28].

In the addition to the numerical values of LOD and $\mathrm{LOQ}$, it is recommended to describe the approach used to specify these validation parameters. Some of the methods of determining LOD and LOQ offered here are rarely described in literature.

\section{Precision}

Precision was stated under repeatability and intermediate precision conditions, and was evaluated by analysing drinking water sample spiked with the standard solutions of both $\mathrm{Cr}$ forms at a concentration of $2.0 \mu \mathrm{g} \mathrm{L}^{-1}$. Repeatability as well as intermediate precision was expressed as a variation coefficient $(\mathrm{CV})$.

Repeatability was determined using the same method and equipment by the same operator within a short period of time. It was estimated by measuring ten replicates of the above-mentioned water sample on the same day. The obtained results were 1.5 and $1.6 \%$ for $\mathrm{Cr}(\mathrm{III})$ and $\mathrm{Cr}(\mathrm{VI})$, respectively. Outcomes of presented repeatability here corresponded with values released previously $[12,15]$.

Intermediate precision was assessed from results obtained with the same method by the same operator over a longer period of time. It was evaluated from the same spiked drinking water sample over three consecutive days. The obtained coefficients of variation- $3.4 \%$ for $\mathrm{Cr}$ (III) and $3.5 \%$ for $\mathrm{Cr}(\mathrm{VI})$, showed that the intermediate precision was satisfactory.

\section{Trueness}

The most frequent approach for estimating the trueness of the method is using particular CRMs. In this study, the trueness was evaluated by the standard addition method, because suitable reference materials for chromium speciation are not available $[10,29,30]$. This method allowed the authors to verify the efficiency of the optimized analytical procedure through determining the recovery of each assayed analyte. The recoveries were tested by analysing drinking water samples $(n=6)$. For this purpose, both chromium species were spiked into four different water matrices at a concentration of $2.0 \mu \mathrm{g} \mathrm{L}^{-1}$. The recovery $(R)$ was calculated according to dependence reported in Guidelines for the In-House Validation of Methods of Analysis, IUPAC [31].

The results of the experiments, carried out on the spiked solution of drinking water are listed in Table 3. As can be seen, the proposed method will reliably detect $\mathrm{Cr}(\mathrm{III})$ and $\mathrm{Cr}(\mathrm{VI})$ present in water below the permissible concentration of total chromium recommended by the WHO. The recoveries for both chromium species were between 93 and $115 \%$ for the collected samples. These outcomes show that the recoveries for $\mathrm{Cr}(\mathrm{III})$ and $\mathrm{Cr}(\mathrm{VI})$ were generally within $\pm 10 \%$ of the nominal spike values. The spiked samples recoveries are considered acceptable if they are within $\pm 25 \%$ the spiked values. This criterion is recommended by the US EPA method 6020A for elemental analyses by ICP-MS, and it was satisfied in this study.

In order to investigate whether the obtained recoveries are significantly different from $100 \%$, the Student's $t$ test was performed. The $t$ value was calculated using the following equation: $t=|1-\bar{R}| / u(\bar{R})$ where $\bar{R}$ denotes the mean value of analyte recovery and $u(\bar{R})$ denotes a standard uncertainty of the mean value of analyte recovery 
Table 3 Results of determination of both chromium species in drinking water samples (without and with an analytical spike) together with expanded uncertainties $(k=2) *$ and recoveries

\begin{tabular}{|c|c|c|c|c|c|c|}
\hline \multirow[t]{3}{*}{ Sample } & \multicolumn{4}{|c|}{ Measured concentration $\left(\mu \mathrm{g} \mathrm{L}^{-1}\right)$} & \multicolumn{2}{|c|}{ Recovery (\%) } \\
\hline & \multicolumn{2}{|c|}{ Real sample } & \multicolumn{2}{|c|}{ Spiked sample } & \multirow[b]{2}{*}{$\operatorname{Cr}(\mathrm{III})$} & \multirow[b]{2}{*}{$\mathrm{Cr}(\mathrm{VI})$} \\
\hline & $\mathrm{Cr}(\mathrm{III})$ & $\mathrm{Cr}(\mathrm{VI})$ & $\mathrm{Cr}(\mathrm{III})$ & $\mathrm{Cr}(\mathrm{VI})$ & & \\
\hline Drinking water 1 & $<\mathrm{LOQ}$ & $0.297 \pm 0.024$ & $2.31 \pm 0.18$ & $2.16 \pm 0.17$ & 115 & 93 \\
\hline Drinking water 2 & $<\mathrm{LOQ}$ & $0.552 \pm 0.044$ & $2.15 \pm 0.17$ & $2.67 \pm 0.21$ & 107 & 106 \\
\hline Drinking water 3 & $<\mathrm{LOQ}$ & $0.578 \pm 0.046$ & $2.05 \pm 0.16$ & $2.58 \pm 0.20$ & 103 & 100 \\
\hline Drinking water 4 & $<\mathrm{LOQ}$ & $1.032 \pm 0.082$ & $1.99 \pm 0.16$ & $3.05 \pm 0.24$ & 100 & 101 \\
\hline
\end{tabular}

* Single-laboratory validation approach was applied to evaluate the expanded uncertainties

which was expressed by an equation found in the VAM Project 3.2.1 [32].

\section{Uncertainty budget}

Scientific research as well as different areas of life such as medicine, industry or environmental protection is based on analytical results which are crucial for all of them. Therefore, it is necessary to assure the quality of the measurements. The evaluation of measurement uncertainty is one of the most useful tools for assessing the reliability of an analytical work. Several possibilities for estimating the uncertainty, based on different sources of information (intra- or inter-laboratory data), have been reported in literature [33, 34].

The classical concept for measurement uncertainty evaluation was described in the Guide to the Expression of Uncertainty in Measurement (GUM) [35] and, subsequently, adapted for the analytical chemistry by the Eurachem organization [36]. This modelling approach encompasses the identification and estimation of numerous possible components of uncertainty of the measurement procedure. The combination of these individual standard uncertainties is included in the uncertainty budget in order to calculate the combined standard uncertainty. The advantage of this approach is that it indicates critical control points of the method. Nevertheless, the modelling concept is time consuming and requires an extensive knowledge of the analytical procedure [26, 37].

An alternative method for the assessment of the uncertainty is based on in-house validation studies including determination of the method performance parameters such as precision (repeatability, intermediate precision and others) and trueness data. The data used in this approach allow the identification of influences from as many relevant uncertainty sources as possible. The single-laboratory validation concept is relatively quick and easy to use because it can be adapted to different types of material that are not in any particular form. Nonetheless, it does not quantify individual components of uncertainty [36].
In this paper, the authors have attempted to estimate the uncertainty in both ways in order to compare and indicate the analytical activities which significantly contribute to the value of the uncertainty. This information may be valuable for the further improvement of the method or its modification for use in similar studies. Uncertainty associated with the sampling was not included in the budget of uncertainty because the laboratory did not participate in the process.

\section{Modelling approach}

The measurement uncertainty evaluation process includes the following steps: (1) description of an analytical procedure and establishing a model equation, (2) estimation of the input and output quantities taken into account in the equation, (3) identification of uncertainty sources, (4) quantification of the standard uncertainty components, (5) application of law of error propagation for calculation of the combined standard uncertainty and (6) estimation of the expanded measurement uncertainty [38, 39].

As it was mentioned above, the first step of the modelling process is a detailed consideration of the measurement procedure to create the mathematical equation that describes the relationship between the output quantity (analytical result) and the input quantities:

$c_{\mathrm{a}}=\frac{\left(A_{\mathrm{S}}-\bar{A}_{\mathrm{ST}}\right)}{b}+\bar{c}_{\mathrm{ST}}$

where $c_{\mathrm{a}}$ denotes an analyte concentration in a drinking water sample $\left(\mu \mathrm{g} \mathrm{L}^{-1}\right), A_{\mathrm{S}}$ peak area of the analyte peak in a sample (counts), $\bar{A}_{\mathrm{ST}}$ mean value of the peak areas of standard solutions (counts), $\bar{c}_{\mathrm{ST}}$ mean value of the concentrations of standard solutions $\left(\mu \mathrm{g} \mathrm{L}^{-1}\right)$ and $b$ slope of the calibration curve (counts/( $\left.\mu \mathrm{g} \mathrm{L}^{-1}\right)$ ).

In order to determine the components influencing the measurement uncertainty in this multi-step analytical procedure, an Ishikawa diagram (cause-and-effect diagram) was created and is shown in Fig. 2. A multiplicity of the factors complicates the diagram and indicates the difficulty of estimating the measurement uncertainty. 


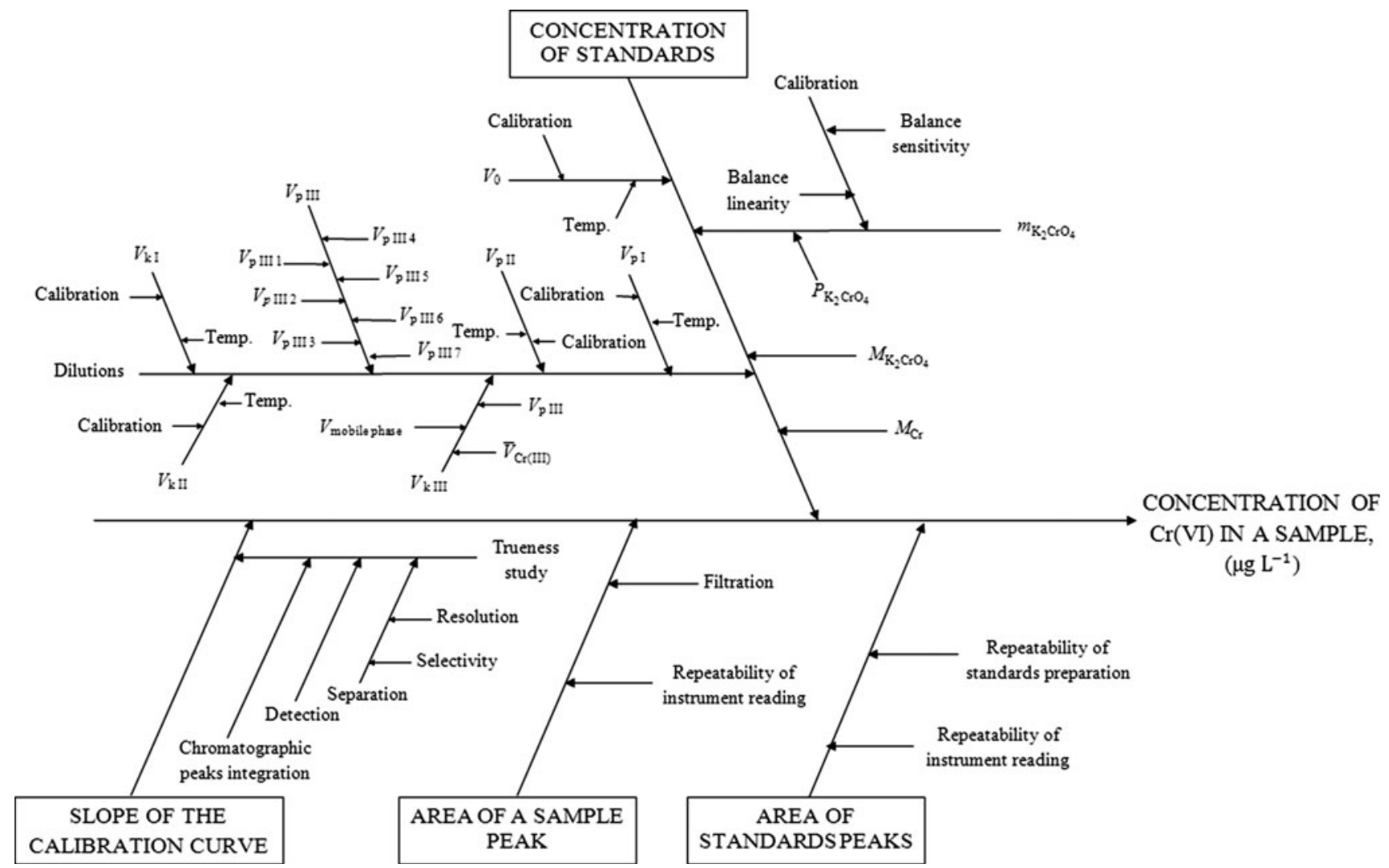

Fig. 2 Ishikawa diagram for $\mathrm{Cr}(\mathrm{VI})$ determination in drinking water samples by the HPLC-ICP-MS. The symbols have the following meaning: $m_{\mathrm{K}_{2} \mathrm{CrO}_{4}}$ denotes the mass of the standard weighed; $M_{\mathrm{K}_{2} \mathrm{CrO}_{4}}$

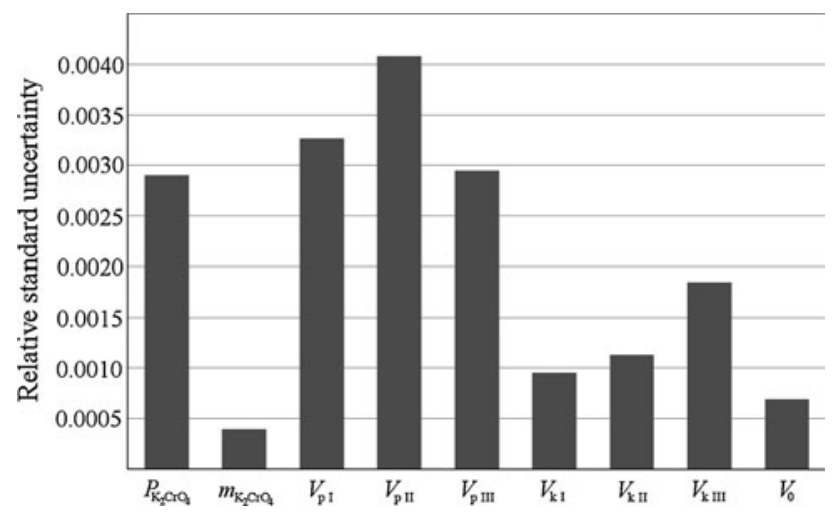

Fig. 3 Relative standard uncertainties of quantities that affect the uncertainty of the concentration of the standard solutions. The symbols have the following meaning: $m_{\mathrm{K}_{2} \mathrm{CrO}_{4}}$ denotes the mass of the standard weighed; $M_{\mathrm{K}_{2} \mathrm{CrO}_{4}}$ the molar mass of the standard; $M_{\mathrm{Cr}}$ the molar mass of chromium; $V_{0}, V_{\mathrm{pI}}, V_{\mathrm{pII}}, V_{\mathrm{pIII}}, V_{\mathrm{kI}}, V_{\mathrm{kII}}, V_{\mathrm{kIII}}$ volumes associated with the preparation of standard solutions; $P_{\mathrm{K}_{2} \mathrm{CrO}_{4}}$ standard purity

The reported diagram and further equations concern $\mathrm{Cr}(\mathrm{VI})$; a similar situation occurs with $\mathrm{Cr}(\mathrm{III})$ (not presented in this paper). The components significantly contributing to the measurement result are represented on the Ishikawa diagram by its main branches, which reflect the molar mass of the standard; $M_{\mathrm{Cr}}$ the molar mass of chromium; $V_{0}$, $V_{\mathrm{pI}}, V_{\mathrm{pII}}, V_{\mathrm{pIII}}, V_{\mathrm{kI}}, V_{\mathrm{kII}}, V_{\mathrm{kIII}}$ volumes associated with the preparation of standard solutions; $P_{\mathrm{K}_{2} \mathrm{CrO}_{4}}$ standard purity

the parameters in the model function. From among these four measurement uncertainty sources, the largest one is associated with the concentrations of standard solutions $\bar{c}_{\mathrm{ST}}$. Before the estimation of the combined standard uncertainty, all the uncertainty components must be expressed as standard uncertainties $u\left(x_{i}\right)$ that were determined in one of the following ways: experimentally from the statistical distribution of the results of sets of repeated measurements by calculating the standard deviation (type A evaluation) or based on other information such as calibration certificates or literature data (type $\mathrm{B}$ evaluation). In the second case, the uncertainty was evaluated from an assumed probability distribution of variables such as purity of analytical standard, temperature effect [34, 39].

The uncertainty of the concentrations of the standard solutions $u\left(\bar{c}_{\mathrm{ST}}\right)$ is one of the most complex components of the combined standard uncertainty. The value of $u\left(\bar{c}_{\mathrm{ST}}\right)$ was determined using the following: relative standard uncertainty of purity of the reagent $u\left(P_{\mathrm{K}_{2} \mathrm{CrO}_{4}}\right) / P_{\mathrm{K}_{2} \mathrm{CrO}_{4}}$,

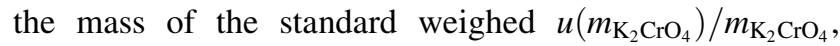

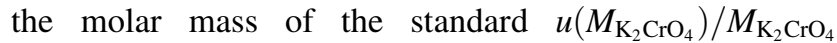
and $u\left(V_{0}\right) / V_{0}, u\left(V_{\mathrm{pI}}\right) / V_{\mathrm{pI}}, u\left(V_{\mathrm{pII}}\right) / V_{\mathrm{pII}}, u\left(V_{\mathrm{pIII}}\right) / V_{\mathrm{pIII}}$, $u\left(V_{\mathrm{kI}}\right) / V_{\mathrm{kI}}, u\left(V_{\mathrm{kII}}\right) / V_{\mathrm{kII}}, u\left(V_{\mathrm{kIII}}\right) / V_{\mathrm{kIII}}$ represent relative standard uncertainties of following dilutions of standard 
solutions which are associated with uncertainties of volumetric equipment (flasks, pipettes) as well as uncertainties of temperature effect. The results are presented in the diagram shown in Fig. 3, and the adequate expression of $u\left(\bar{c}_{\mathrm{ST}}\right)$ is demonstrated below:

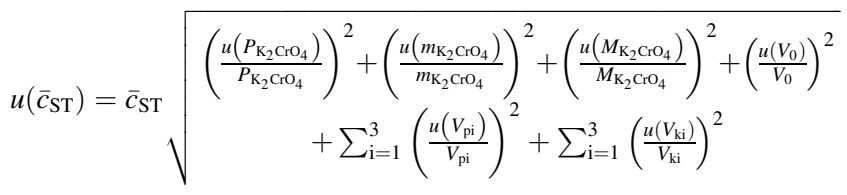

The relative standard uncertainty of the molar mass of the $\mathrm{Cr}(\mathrm{VI})$ standard has a secondary influence on the $u\left(\bar{c}_{\mathrm{ST}}\right)$ (it is about 16 times smaller than the relative standard uncertainty of mass of $\mathrm{K}_{2} \mathrm{CrO}_{4}$ ); therefore, this component is not included in the Fig. 3. In conclusion, it could be ignored in future calculation.

The uncertainties related to the slope of the calibration curve, peak area of a sample and mean value of all the peak areas of the standard solutions were evaluated. Uncertainties of peak areas mainly take into account the variability of the mobile phase flow rate and its composition, as well as the repeatability and drift of an instrument, which concerns the uncertainty of the slope of the calibration curve. The values of $u(b), u\left(A_{\mathrm{S}}\right)$ and $u\left(\bar{c}_{\mathrm{ST}}\right)$ were quantified from the relevant relationships (Eq. 3):

$u(x)=\frac{s_{\text {residual }}}{x}$

where $x$ denotes, respectively, $b, A_{\mathrm{S}}$ or $\bar{A}_{\mathrm{ST}} ; s_{\text {residual }}$ denotes the residual standard deviation of the calibration curve; $x_{b}$ is defined as $\sqrt{\sum_{i=1}^{n}\left(c_{\mathrm{ST}_{i}}-\bar{c}_{\mathrm{ST}}\right)^{2}}$, where $c_{\mathrm{ST}_{i}}$ denotes the concentration of the $i$ th calibration standard; $\bar{c}_{\mathrm{ST}}$ a mean value of the concentrations of standard solutions; $x_{A_{\mathrm{S}}}$ is expressed as $\sqrt{n}$, where $n$ indicates the number of replicated measurements of a sample; $x_{\bar{A}_{\mathrm{ST}}}$ is $\sqrt{l}$, where $l$ presents the total number of standard solutions used for plotting the calibration curve.

Having determined the uncertainty components of the identified uncertainty sources, the next step was to calculate the combined standard measurement uncertainty $u_{c}(x)$ referring to the analytical process, using the propagation principles (Eq. 4).

$u_{c}\left(c_{a}\right)=\sqrt{\frac{1}{b^{2}} u^{2}\left(A_{\mathrm{S}}\right)+\frac{1}{b^{2}} u^{2}\left(\bar{A}_{\mathrm{ST}}\right)+\frac{\left(A_{\mathrm{S}}-\bar{A}_{\mathrm{ST}}\right)^{2}}{b^{4}} u^{2}(b)+u^{2}\left(\bar{c}_{\mathrm{ST}}\right)}$

where $u_{c}\left(c_{a}\right)$ denotes the combined standard uncertainty of an analyte concentration in a given drinking water sample. The parameters used in this equation have been described above.

The final step consists of estimating the expanded uncertainty of the result of a measurement, $U$. This value was obtained by multiplying the combined standard uncertainty by a coverage factor $k$, which is usually selected as $k=2$ what allows a level of confidence of approximately $p=95 \%$ to be accomplished [40]. Table 4 summarizes the estimated uncertainties of both chromium species, referring to the method studied in this article.

In order to evaluate the analytical procedure, the contribution of the individual components to the combined standard uncertainty was investigated. Each of the uncertainty components was presented as the percentage of all contributions. As can be seen from the results obtained (Table 4), the largest influence came from $u^{2}\left(\bar{c}_{\mathrm{ST}}\right)$ which contributed $39 \%$ for $\mathrm{Cr}(\mathrm{III})$ and $42 \%$ for $\mathrm{Cr}(\mathrm{VI})$ to the combined standard uncertainty. Other discussed components of the uncertainty budget, such as slope of the calibration curve, areas of measured samples and standard solutions, have a lesser effect on $u_{c}\left(c_{\mathrm{a}}\right)$ for both analytes. Based on the results, it can be concluded that the preparation of the standard solutions is a critical point of analysis (often overlooked in other articles as a factor slightly affecting the value of the combined standard uncertainty), and in future analytical work, the element $u\left(\bar{c}_{\mathrm{ST}}\right)$ will require the greatest caution.

The proposed approach for the quantification of the measurement uncertainty for $\mathrm{Cr}$ species in drinking water samples is valid only in the analytical range of the validated method. Outside this range, a new evaluation of uncertainty budget needs to be carried out.

\section{Single-laboratory validation approach}

Alternatively, measurement uncertainties of $\mathrm{Cr}(\mathrm{III})$ and $\mathrm{Cr}(\mathrm{VI})$ concentrations were evaluated based on method validation data, assuming that they encompass the whole analytical process [37].

All the parameters contributing to the combined standard uncertainty were determined from the statistical evaluation of the repeated measurements. After identification of relevant sources of uncertainty, they were combined to quantify the combined standard uncertainty according to the law of error propagation. In the final stage, as in the modelling concept, expanded uncertainty was calculated for a level of confidence of approximately $p=95 \%$ corresponding to a coverage factor of $k=2$. The parameters affecting the measurement uncertainty of the analytical result were grouped into two main components: precision and trueness of the method.

The overall method precision was evaluated from intermediate precision. This component presents a significant source of measurement uncertainty, so it requires detailed examination to avoid overestimation or underestimation of the combined standard uncertainty. Sources of uncertainty related to volumetric measuring equipment, 
Table 4 Evaluation of combined standard uncertainty and expanded uncertainty for determination of chromium species in drinking water samples

\begin{tabular}{|c|c|c|c|c|c|c|}
\hline Analyte & $u^{2}\left(A_{\mathrm{S}}\right)(\text { counts })^{2}$ & $u^{2}\left(\bar{A}_{\mathrm{ST}}\right)(\text { counts })^{2}$ & $u^{2}(b),\left(\text { counts } / \mu \mathrm{g} \mathrm{L}^{-1}\right)^{2}$ & $\left.u^{2} \bar{c}_{\mathrm{ST}}(\mu \mathrm{g} \mathrm{L})^{-1}\right)^{2}$ & $u_{c}\left(c_{\mathrm{a}}\right)\left(\mu \mathrm{g} \mathrm{L}^{-1}\right)$ & $U(k=2)(\%)$ \\
\hline \multicolumn{7}{|c|}{ Modelling approach } \\
\hline $\mathrm{Cr}(\mathrm{III})$ & 0.00059 & 0.00044 & 0.00025 & 0.00080 & 0.046 & 4.4 \\
\hline $\mathrm{Cr}(\mathrm{VI})$ & 0.00055 & 0.00041 & 0.00021 & 0.00085 & 0.045 & 4.2 \\
\hline Analyte & \multicolumn{2}{|c|}{$u^{2}\left(s_{\mathrm{p}}\right)$} & $u^{2}(\bar{R})^{\prime}$ & \multicolumn{2}{|c|}{$u_{c}\left(c_{\mathrm{a}}\right)\left(\mu \mathrm{g} \mathrm{L}^{-1}\right)$} & $U(k=2)(\%)$ \\
\hline \multicolumn{7}{|c|}{ Single-laboratory validation approach } \\
\hline $\mathrm{Cr}(\mathrm{III})$ & \multicolumn{2}{|c|}{0.0011} & 0.00041 & \multicolumn{2}{|l|}{0.039} & 7.8 \\
\hline $\mathrm{Cr}(\mathrm{VI})$ & \multicolumn{2}{|c|}{0.0012} & 0.00037 & \multicolumn{2}{|l|}{0.040} & 7.9 \\
\hline
\end{tabular}

influences of environmental conditions, repeatability and drift of an instrument were exactly covered by the intermediate precision. The standard uncertainty of the method precision $u\left(s_{P_{i}}\right)$ was calculated as a relative standard deviation $[32,41]$. The obtained values are given in Table 4.

Trueness of the method was estimated from recovery of the spiked samples of drinking water. Both chromium species were spiked into water matrices at a concentration of $2.0 \mu \mathrm{g} \mathrm{L}^{-1}$. The Student's $t$ test was performed to prove the trueness of the method. It showed that the mean value of analyte recovery was not significantly different from the theoretical reference set at 1 , in the case of $\mathrm{Cr}(\mathrm{VI})$. Therefore, the method was not biased. The standard uncertainty of recovery $u(\bar{R})^{\prime}$ was calculated according to the formula [32]:

$u(\bar{R})^{\prime}=\frac{t_{\text {crit }} u(\bar{R})}{1.96}$

where $t_{\text {crit }}$ denotes critical value for $n-1$ degrees of freedom at accepted level of significance $\alpha=0.05$. On the opposite side, the $\mathrm{Cr}$ (III) recovery component turned out to be significant for the Student's $t$ test. Nevertheless, in the regular application of the method, the difference between the obtained $\bar{R}$ value and 1 is not considerable, so the correction factor was not included in the measurement result. In this situation, the uncertainty associated with recovery must be enlarged to take the uncorrected bias into account. The modified standard uncertainty of recovery $u(\bar{R})^{\prime}$ was given by (Eq. 6) [32]:

$u(\bar{R})^{\prime}=\sqrt{\left(\frac{1-\bar{R}}{t_{\text {crit }}}\right)^{2}+u^{2}(\bar{R})}$

In the next step, the combined standard uncertainty $u_{c}\left(c_{\mathrm{a}}\right)$ was calculated using the law of propagation (Eq. 7).

$u_{c}\left(c_{\mathrm{a}}\right)=c_{\mathrm{a}} \sqrt{u^{2}\left(s_{P_{i}}\right)+u^{2}(\bar{R})^{\prime}}$

where $u\left(s_{P_{i}}\right)$ denotes the standard uncertainty of precision and $u(\bar{R})^{\prime}$ denotes the standard uncertainty of recovery.
The obtained results are provided in Table 4, and they present contributions from the trueness of the method and from the precision that are the most relevant uncertainty components associated with the method.

The standard uncertainty of the precision component has a greater influence on the combined standard uncertainty; as expected, it includes random errors from many variables. The estimated results of the expanded uncertainty $U(k=2)$ are given in Table 4 .

\section{Conclusions}

Up to now, the speciation analysis of chromium has been studied mostly in environmental samples. The fast and accurate HPLC-ICP-MS method enables the detection and quantification of $\mathrm{Cr}(\mathrm{III})$ and $\mathrm{Cr}(\mathrm{VI})$ in drinking waters samples. LOD was determined by the modified blank determination method. The obtained results were compared with values obtained by other researchers (Table 2). In publications on chromium speciation, LOD is most often calculated by the simplest method-as the 3 times standard deviation of the background. The regression for each species is 0.9999, thus demonstrating the linearity and reproducibility of the method. Quantitative analysis of the spiked samples (Table 4) shows that recoveries for both chromium species were between 93 and $115 \%$. The measurement uncertainties of the HPLC-ICP-MS method were determined in two different ways: the modelling approach and the single-laboratory validation approach. The expanded uncertainties $(k=2)$ of the results were found to be 4.4 and $4.2 \%$ for $\mathrm{Cr}$ (III) and $\mathrm{Cr}(\mathrm{VI})$, respectively, with application of the first method. Based on method validation data, the expanded uncertainties $(k=2)$ of the final results were calculated to be $7.8 \%$ for $\mathrm{Cr}$ (III) and $7.9 \%$ for $\mathrm{Cr}(\mathrm{VI})$. A lower value of the uncertainty obtained by the first method is related to the lower variability of factors. Variability factors can be taken into account only in the values recognized in the model 
equation. The component of uncertainty associated with the precision of sample preparation, standard solutions and measuring operation are not considered sufficiently. In addition, uncertainty related to the trueness of the method is expressed only by the slope of the calibration curve and this may cause an underestimation.

In conclusion, for the validation of new methods the first approach is more useful because it reveals their critical points and clearly indicates how the uncertainty of the individual analytical activities contributes to the overall measurement uncertainty. Knowing the uncertainty of each component, the future procedures can be planned more carefully. However, it should be remembered that the modelling concept does not allow to take into account all relevant components of the uncertainty. Moreover, it may be considered as demanding in application.

The second approach based on the validation of the analytical method is advantageous, because the parameters of the validation process such as precision and trueness can deliver considerable quantities of the data required for the evaluation of the uncertainty measurement. It is well known that these parameters are a crucial part of quantitative analysis.

The presented method was proved to be suitable for the determination of chromium species in drinking water. As this method is a comparative method, the metrologically proper way to prove the competence of the result was demonstrated.

Acknowledgments This work was financially supported by the Research Project of the Polish Ministry of Science and Higher Education, MNiSzW N N204 140439.

Open Access This article is distributed under the terms of the Creative Commons Attribution License which permits any use, distribution, and reproduction in any medium, provided the original author(s) and the source are credited.

\section{References}

1. Komorowicz I, Barałkiewicz D (2011) Arsenic and its speciation in water samples by high performance liquid chromatography inductively coupled plasma mass spectrometry-last decade review. Talanta 84:247-261

2. Kuo CY, Jiang SJ, Sahayam AC (2007) Speciation of chromium and vanadium in environmental samples using HPLC-DRCICP-MS. J Anal At Spectrom 22:636-641

3. Wang HJ, Du XM, Wang M, Wang TC, Ou-Yang H, Wang B, Zhu MT, Wang Y, Jia G, Feng WY (2010) Using ion-pair reversed-phase HPLC ICP-MS to simultaneously determine $\mathrm{Cr}(\mathrm{III})$ and $\mathrm{Cr}(\mathrm{VI})$ in urine of chromate workers. Talanta 81:1856-1860

4. Bednar AJ, Kirgan RA, Jones WT (2009) Comparison of standard and reaction cell inductively coupled plasma mass spectrometry in the determination of chromium and selenium species by HPLC-ICP-MS. Anal Chim Acta 632:27-34
5. Xing L, Beauchemin D (2010) Chromium speciation at trace level in potable water using hyphenated ion exchange chromatography and inductively coupled plasma mass spectrometry with collision/reaction interface. J Anal At Spectrom 25:1046-1055

6. Kotaś J, Stasicka Z (2000) Chromium occurrence in the environment and methods of its speciation. Environ Pollut 107:263-283

7. Metze D, Jakubowski N, Klockow D (2005) In: Cornelis R, Crews H, Caruso J, Heumann KG Handbook of elemental speciation II: species in the environment, food, medicine and occupational health. Wiley, New York

8. Wrobel K, Caruso JA (2010) In: Gross ML, Caprioli RM The encyclopedia of mass spectrometry, volume 5: elemental and isotope ratio mass spectrometry. Elsevier, Oxford

9. Eiden G, Barinaga CJ, Koppenaal DW (2010) In: Gross ML, Caprioli RM The encyclopedia of mass spectrometry, volume 5: elemental and isotope ratio mass spectrometry. Elsevier, Oxford

10. Chen ZL, Megharaj M, Naidu R (2007) Removal of interferences in the speciation of chromium using an octopole reaction system in ion chromatography with inductively coupled plasma mass spectrometry. Talanta 73:948-952

11. Vonderheide AP, Meija J, Tepperman K, Puga A, Pinhas AR, States JC, Caruso JA (2004) Retention of Cr(III) by high-performance chelation ion chromatography interfaced to inductivelycoupled plasma mass spectrometric detection with collision cell. J Chromatogr A 1024:129-137

12. Wolf RE, Morrison JM, Goldhaber MB (2007) Simultaneous determination of $\mathrm{Cr}$ (III) and $\mathrm{Cr}(\mathrm{VI})$ using reversed-phased ionpairing liquid chromatography with dynamic reaction cell inductively coupled plasma mass spectrometry. J Anal At Spectrom 22:1051-1060

13. Threeprom J, Purachaka S, Potipan L (2005) Simultaneous determination of $\mathrm{Cr}(\mathrm{III})$-EDTA and $\mathrm{Cr}(\mathrm{VI})$ by ion interaction chromatography using a C18 column. J Chromatogr A 1073(1-2): 291-295

14. PN-EN ISO/IEC 17025:2005 General requirements for the competence of testing and calibration laboratories

15. Chang YL, Jiang SJ (2001) Determination of chromium species in water samples by liquid chromatography-inductively coupled plasma-dynamic reaction cell-mass spectrometry. J Anal At Spectrom 16:858-862

16. Neubauer K, Reuter W, Perrone P (2003) Chromium speciation in water by HPLC/ICP-MS. Application Note Perkin Elmer

17. Graham AM, Wadhawan AR, Bouwer EJ (2009) Chromium occurrence and speciation in Baltimore Harbor sediments and porewater, Baltimore, Maryland, USA. Environ Toxicol Chem 28:471-480

18. Konieczka P, Namieśnik J (2009) Quality assurance and quality control in the analytical chemical laboratory. A practical approach. Taylor \& Francis Group, Boca Raton

19. EURACHEM Guide (1998) The fitness for purpose of analytical methods: a laboratory guide to method validation and related topics. LGC, Teddington

20. International Conference on Harmonisation of Technical Requirements for Registration of Pharmaceuticals for Human Use (2005) ICH Guideline Q2(R1): validation of analytical procedures: text and methodology, http://www.ich.org/. Accessed 12 Feb 2013

21. Vanhaecke F, Saverwyns S, De Wannemacker G, Moens L, Dams R (2000) Comparison of the application of higher mass resolution and cool plasma conditions to avoid spectral interferences in $\mathrm{Cr}(\mathrm{III}) / \mathrm{Cr}(\mathrm{VI})$ speciation by means of high-performance liquid chromatography-inductively coupled plasma mass spectrometry. Anal Chim Acta 419:55-64

22. Séby F, Charles S, Gagean M, Garraud H, Donard OFX (2003) Chromium speciation by hyphenation of high-performance liquid chromatography to inductively coupled plasma-mass 
spectrometry-study of the influence of interfering ions. J Anal At Spectrom 18:1386-1390

23. Gürleyük H, Wallschläger D (2001) Determination of chromium(III) and chromium(VI) using suppressed ion chromatography inductively coupled plasma mass spectrometry. J Anal At Spectrom 16:926-930

24. Voica C, Dehelean A, Pamula A (2009) Method validation for determination of heavy metals in wine and slightly alcoholic beverages by ICP-MS. J Phys Conf Ser 182:012036

25. Leufroy A, Noël L, Dufailly V, Beauchemin D, Guérin T (2011) Determination of seven arsenic species in seafood by ion exchange chromatography coupled to inductively coupled plasma-mass spectrometry following microwave assisted extraction: method validation and occurrence data. Talanta 83:770-779

26. Chudzinska M, Debska A, Baralkiewicz D (2012) Method validation for determination of 13 elements in honey samples by ICPMS. Accred Qual Assur 17:65-73

27. Delgado B, Ayala JH, González V, Afonso AM (2008) Estimation of uncertainty in the analysis of carbonyl compounds by HPLC-UV using DNPH derivatization. J Liq Chromatogr Relat Technol 31:361-381

28. Baranowska I, Magiera S (2011) Analysis of isoflavones and flavonoids in human urine by UHPLC. Anal Bioanal Chem 399:3211-3219

29. Xie Q, Kerrich R, Irving E, Liber K, Abou-Shakra F (2002) Determination of five arsenic species in aqueous samples by HPLC coupled with a hexapole collision cell ICP-MS. J Anal At Spectrom 17:1037-1041

30. Castillo A, Roig-Navarro AF, Pozo OJ (2008) Capabilities of microbore columns coupled to inductively coupled plasma mass spectrometry in speciation of arsenic and selenium. J Chromatogr A $1202: 132-137$

31. International Union of Pure Applied Chemistry (1999) Harmonised Guidelines for the In-House Validation of Methods of
Analysis, Budapest. http://old.iupac.org/divisions/V/501/draftoct 19.pdf. Accessed 12 Feb 2013

32. VAM Project 3.2.1 (2000) Development and harmonisation of measurement uncertainty principles, part (d): protocol for uncertainty evaluation from validation data. LGC, Teddington

33. EURACHEM/CITAC Guide (2012) Quantifying uncertainty in analytical measurement, 3rd edn. LGC, Teddington

34. Quintela M, Báguena J, Gotor G, Blanco MJ, Broto F (2012) Estimation of the uncertainty associated with the results based on the validation of chromatographic analysis procedures: application to the determination of chlorides by high performance liquid chromatography and of fatty acids by high resolution gas chromatography. J Chromatogr A 1223:107-117

35. Jókai Z, Fodor P (2009) Evaluation of the uncertainty statement in the case of mercury speciation analysis. J Anal At Spectrom 24:1229-1236

36. International Organization for Standardization (1993) Guide to the expression of uncertainty in measurement. Geneva

37. EURACHEM/CITAC Guide (2007) Measurement uncertainty arising from sampling: a guide to methods and approaches, 1st edn. LGC, Teddington

38. Barwick VJ, Ellison SLR, Frairman B (1999) Estimation of uncertainties in ICP-MS analysis: a practical methodology. J Chromatogr A 394:281-291

39. Tomić T, Nasipak NU, Babić S (2012) Estimating measurement uncertainty in high-performance liquid chromatography methods. Accred Qual Assur 17:291-300

40. EUROLAB (2007) Measurement uncertainty revisited: alternative approaches to uncertainty evaluation. http://www.eurolab. org. Accessed 12 Feb 2013

41. Murtas S, Gaggioli A, von Hunolstein C (2012) Quantifying uncertainty in determination of polysaccharides in glycoconjugate vaccines based on in-house validation data. Accred Qual Assur 17:177-182 